\title{
A force field for mackinawite surface simulations in an aqueous environment
}

\author{
Umberto Terranova $^{1} \cdot$ Nora H. de Leeuw ${ }^{1,2}$
}

Received: 13 October 2015 / Accepted: 30 November 2015 / Published online: 5 February 2016

(C) The Author(s) 2016. This article is published with open access at Springerlink.com

\begin{abstract}
We introduce a force field for the description of the mackinawite/water interface, which we derive by refining, and consistently merging with the SPC/Fw model of water, a set of existing interatomic potentials for the mineral. The thermal behaviour predicted for bulk mackinawite is in good agreement with experiment. The adsorption of water on the low-index surfaces of mackinawite reproduces results from density functional theory calculations at different water coverages, while the behaviour of water intercalated into the mineral is also remarkably similar to that from ab initio results. The force field is therefore suitable to model bulk mackinawite and its surfaces in an aqueous environment.
\end{abstract}

Keywords Mackinawite/water interface $\cdot$ Force field · Molecular dynamics

\section{Introduction}

Iron-sulphide minerals in aqueous environment are of considerable interest in geochemistry. Due to its relevance to areas ranging from acid mine drainage $[1,2]$ to a prominent theory on the origin of life [3], the interface between pyrite $\left(\mathrm{FeS}_{2}\right)$, the most common sulphide mineral, and water has

Published as part of the special collection of articles "CHITEL 2015 - Torino - Italy".

Umberto Terranova

u.terranova@ucl.ac.uk

1 Department of Chemistry, University College London, London WC1H 0AJ, UK

2 School of Chemistry, Cardiff University, Cardiff CF10 3AT, UK attracted considerable experimental $[4,5]$ and theoretical attention [6-10].

Like pyrite [11], mackinawite (FeS) is an exceptional scavenger for heavy metals in water $[12,13]$, while the similarity between its structural unit [14] and reactive biological clusters [15] has suggested that FeS structures could have catalysed the formation of the first prebiotic molecules in deep sea hydrothermal vents $[16,17]$. However, contrary to $\mathrm{FeS}_{2}$, the interface between water and $\mathrm{FeS}$ has not been widely investigated [18, 19], in part because of the lack of force field parameters for the system.

In previous work, we have derived a force field, based on pairwise interactions, for molecular mechanics (MM) simulations of mackinawite [20]. In this model, each interaction can be written as a function of the interatomic distances $r_{i j}$ :

$U_{i j}=A \exp \left(-\frac{r_{i j}}{\rho}\right)-\frac{C}{r_{i j}^{6}}+\frac{q_{i} q_{j}}{r_{i j}}$,

where $A, \rho$, and $C$ are the coefficients of Buckingham potentials, and $q_{i}$ the electrostatic charges of the atoms. In addition, to take into account polarisability effects, each sulphur atom is represented by a core and a massless shell (S-S $\left.\mathrm{S}_{\text {shell }}\right)$, which interact through a harmonic potential [21]:

$U_{i j}=\frac{1}{2} k_{s} r_{i j}^{2}$,

where $k_{\mathrm{s}}$ is the shell force constant, and $r_{i j}$ the core-shell distance. The parameters, reported in Table 1, have highlighted the stability of the (001) surface compared to all other surfaces, in agreement with ab initio calculations [22] and experimental findings [23].

Here, we expand the FeS interatomic potential model to include its interaction with water, the latter described by 
Table 1 Force field parameters for FeS from reference [20]

\begin{tabular}{llll}
\hline Buckingham $^{\mathrm{a}}$ & $A(\mathrm{eV})$ & $\rho(\AA)$ & $C\left(\mathrm{eV}^{6}\right)$ \\
\hline Fe-S & 1000.00 & 0.3200 & 0.0 \\
$\mathrm{~S}_{\text {shell }}-\mathrm{S}_{\text {shell }}$ & 9201.82 & 0.3147 & 130.0 \\
Harmonic three body $^{\mathrm{b}, \mathrm{c}}$ & $\theta_{0}\left({ }^{\circ}\right)$ & $k_{\mathrm{tb}}\left(\mathrm{eV} \mathrm{rad}^{-2}\right)$ & \\
$\mathrm{S}-\mathrm{Fe}-\mathrm{S}$ & 109.47 & 3.0 & \\
Harmonic shell & $k_{\mathrm{s}}\left(\mathrm{eV} \AA^{-2}\right)$ & & \\
$\mathrm{S}-\mathrm{S}_{\text {shell }}$ & 23.0 & & \\
Species & $q(\mathrm{e})$ & & \\
$\mathrm{Fe}$ & +2.000 & & \\
$\mathrm{~S}$ & +1.357 & & \\
$\mathrm{~S}_{\text {shell }}$ & -3.357 & &
\end{tabular}

${ }^{\mathrm{a}}$ Unless specified, a cut-off of $9.0 \AA$ was adopted. ${ }^{\mathrm{b}}$ Added in this work (see Sect. 3.1). ${ }^{\mathrm{c}}$ A cut-off of $3.0 \AA$ was adopted

the popular SPC/Fw model [24]. In order to achieve this, we first refined the existing $\mathrm{FeS}$ interatomic potentials, followed by the derivation of the missing $\mathrm{FeS}-\mathrm{H}_{2} \mathrm{O}$ parameters, by fitting with two-body interactions the ab initio intermolecular energies between the $\mathrm{FeS}$ molecule $\left(\mathrm{FeS} \mathrm{S}_{\mathrm{mol}}\right)$ and $\mathrm{H}_{2} \mathrm{O}$. Finally, we validated the force field against density functional theory (DFT) calculations of water on the low-index surfaces of $\mathrm{FeS}$ and DFT-based molecular dynamics (MD) of intercalated water. In both cases, our model reproduced the ab initio findings. The force field is therefore suitable to model bulk mackinawite and its surfaces in an aqueous environment.

\section{Methods}

\subsection{Molecular dynamics}

MD simulations of bulk mackinawite were carried out in the NPT ensemble with the semi-anisotropic constraint, as implemented in DL_POLY_4 [25]. We have employed the Nosé-Hoover algorithm [26], with target temperature and pressure of $300 \mathrm{~K}$ and $1 \mathrm{~atm}$. The thermostat and barostat had a relaxation time of 0.1 ps. The $6 \times 6 \times 5$ simulation supercells, containing 180 tetragonal $\mathrm{Fe}_{2} \mathrm{~S}_{2}$ units, were equilibrated for $2 \mathrm{~ns}$, and the data were collected during the following 1-ns run. The time step corresponded to $0.5 \mathrm{fs}$. The Smoothed Particle Mesh Ewald was used to calculate the long-range electrostatics [27], with a precision of $10^{-6}$. The real space part of the electrostatics calculations had a cut-off of $9.0 \AA$ A. Following the adiabatic method proposed by Mitchell et al. [28], shells were assigned a mass of 0.1 Da.

MD simulations of water confined in $\mathrm{FeS}$ sheets were carried out in the NVT ensemble, with a target temperature of $500 \mathrm{~K}$. The system was equilibrated for $500 \mathrm{ps,} \mathrm{and} \mathrm{the}$ data were collected during the following $500 \mathrm{ps.} \mathrm{The} \mathrm{time}$ step corresponded to $0.5 \mathrm{fs}$. A precision of $10^{-6}$ was used in the Smoothed Particle Mesh Ewald. A cut-off of $8.3 \AA$ was used for the real space part of the electrostatics calculations and the Van der Waals potentials. In the adiabatic method, a mass of 0.1 Da was given to the shells.

\subsection{Ab initio interaction energies}

We have employed Gaussian 09 [29] to derive the ab initio interaction energies, at the MP2 level of theory, between the atom pair $\mathrm{FeS}_{\mathrm{mol}}$ (in its lowest energy quintet spin multiplicity) and $\mathrm{H}_{2} \mathrm{O}$. The geometries of the two molecules corresponded to those at equilibrium in their respective force fields ( $\mathrm{Fe}-\mathrm{S}=1.893 \AA$, O-H $=1.012 \AA$, H-O-H $=113.24^{\circ}$ ). The basis set chosen was the AUG-cc-pVTZ [30], particularly suitable for post-Hartee-Fock methods. Counterpoise corrections were taken into account to avoid basis set superposition effects [31]. A total of 41 reference energies were collected in both profiles.

\subsection{Fitting procedure}

We have used GULP $4.2[32,33]$ to fit the interatomic interactions between $\mathrm{FeS}$ and $\mathrm{H}_{2} \mathrm{O}$ to the energy surfaces derived ab initio. In GULP, the fitting procedure is carried out by varying the parameters, so as to minimise the "sum of squares" of the differences between the classical and $a b$ initio reference energies. In order to take into account the presence of the shell, we have adopted the simultaneous fitting scheme, where the shell coordinates are also treated as fitting parameters.

\subsection{Geometry optimisations}

DFT optimisations were performed with VASP 5.3 [34, 35], taking into account the Van der Waals correction as implemented in the DFT-D2 method of Grimme [36]. As in our previous works [22, 37], FeS was modelled in the nonmagnetic state. We have employed the PBE functional [38], together with the projector augmented wave method to model the core-electron interaction [39]. Specifically, we have treated explicitly the $4 \mathrm{~s}, 3 \mathrm{~d}$, and $3 \mathrm{p}$ electrons of $\mathrm{Fe}$, the $3 \mathrm{~s}$ and $3 \mathrm{p}$ of $\mathrm{S}$, the $2 \mathrm{~s}$ and $2 \mathrm{p}$ of $\mathrm{O}$, and the $1 \mathrm{~s}$ of $\mathrm{H}$. The plane wave cut-off was $500 \mathrm{eV}$, and bulk and surface calculations were performed with, respectively, $13 \times 13 \times 13$ and $3 \times 3 \times 1$ Monkhorst-Pack grids [40].

MM optimisations with the force field presented in this work have been carried out with GULP 4.2, with an accuracy of $10^{-8}$ in the Ewald summation.

In both approaches, we have employed a $1 \times 1 \times 1$ bulk unit cell (one $\mathrm{Fe}_{2} \mathrm{~S}_{2}$ unit) to derive the lattice parameters, 
and subsequently we have used the relaxed bulk structures to construct $3 \times 3 \times 4$ surface unit cells. In the surface calculations, a vacuum spacing of around $15 \AA$ was introduced to avoid spurious interactions between replica atoms.

\section{Results}

\subsection{Refining the existing $\mathrm{FeS}$ force field}

The FeS force field already in the literature had thus far only been employed to derive properties of the crystal at zero temperature [20]. However, it is also important that thermal properties are reproduced correctly. Unfortunately, we noted that the existing force field, when employed in $\mathrm{MD}$, does not maintain the correct tetrahedral geometry of the iron atoms. After a few ps of dynamics, one of the four bonds of each $\mathrm{FeS}_{4}$ tetrahedron is lost, leaving the iron in a trigonal-planar coordination. In order to effectively solve this issue, we have added a three-body term between the $\mathrm{S}-\mathrm{Fe}-\mathrm{S}$ angles:

$U_{i j k}=\frac{1}{2} k_{\mathrm{tb}}\left(\theta_{i j k}-\theta_{0}\right)^{2}$,

where $\theta_{0}$ is the tetrahedral $\mathrm{S}-\mathrm{Fe}-\mathrm{S}$ angle, and $k_{\mathrm{tb}}$ the associated force constant. We have adopted for $k_{\mathrm{tb}}$ a convenient value of $3.0 \mathrm{eV} \mathrm{rad}^{-2}$ (cut-off $3.0 \AA$ ), which we have validated in Sect. 3.2. From here on, and throughout the paper, we will always refer to the refined FeS force field described in this subsection (Table 1) and not to the previous potential parameters.

\subsection{Thermal behaviour of mackinawite}

First, we have applied the force field in MD simulations in the NPT ensemble with the semi-anisotropic constraint to study the thermal behaviour of mackinawite. Under ambient conditions, we obtain for the lattice constants $a$ and $c$ the values of 3.680 and 5.045, respectively, which are in very good agreement with the experimental values (3.674 and 5.033 [41]). The average $\mathrm{Fe}-\mathrm{Fe}$ and $\mathrm{Fe}-\mathrm{S}$ distances during the MD simulation correspond to 2.606 and 2.259 $\AA$, which again match the experimental values (2.598 and $2.256[41])$.

We illustrate in Fig. 1 the dependence of the lattice parameters on the temperature, as predicted by our force field. Following the approach by Lennie et al. [42], who have used X-ray diffraction to estimate the linear expansion coefficients of mackinawite in the temperature range 293-453 K, we have fitted the data with a linear function and used its slope to derive the coefficients:

$\alpha_{a}=\frac{1}{a_{0}} \frac{\partial a}{\partial T}$,
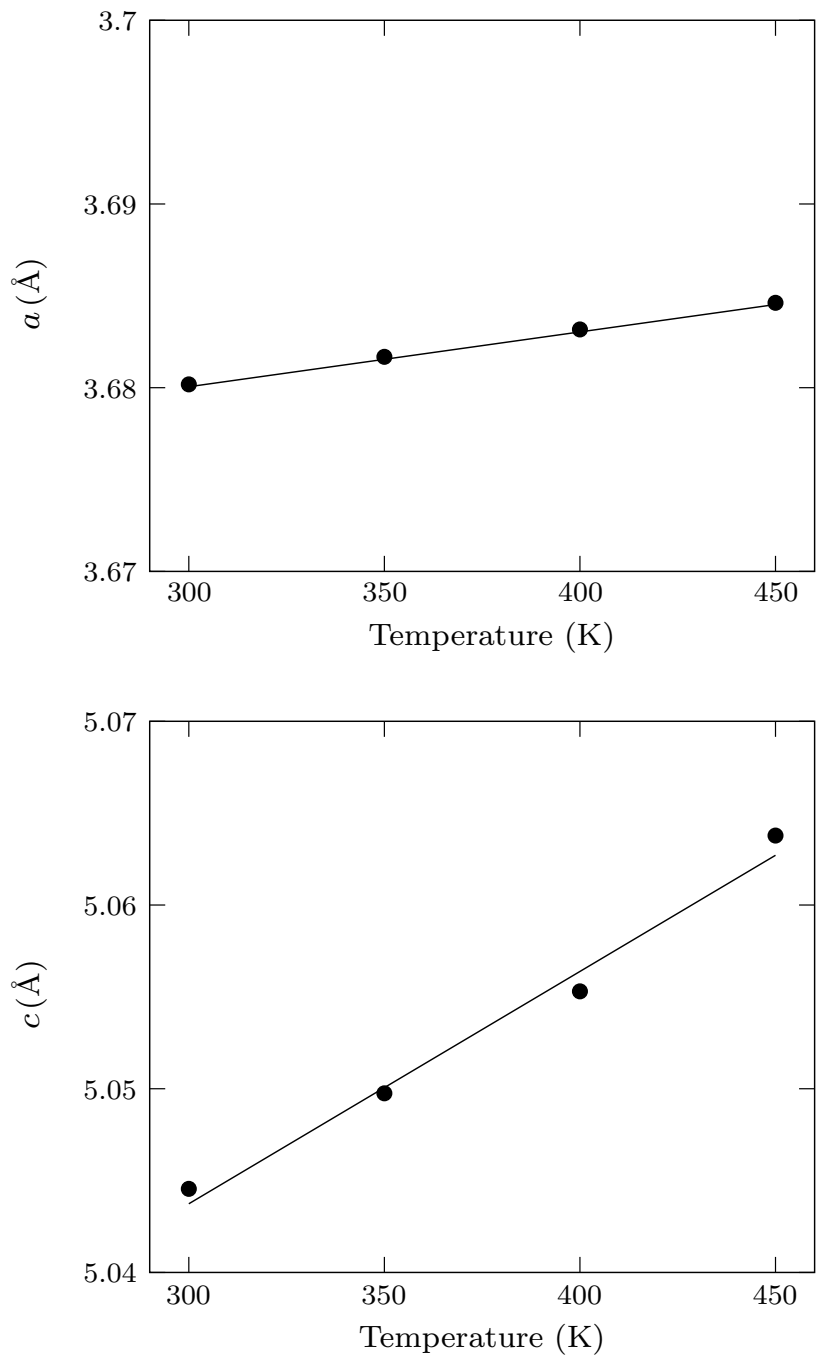

Fig. 1 Lattice constants of mackinawite with respect to the temperature ( $p=1$ bar). The fitted lines are also shown

and

$\alpha_{c}=\frac{1}{c_{0}} \frac{\partial c}{\partial T}$,

where $a_{0}$ and $c_{0}$ are the reference lattice parameters at $300 \mathrm{~K}$. The resulting $\alpha_{a}=8.1 \times 10^{-6} \mathrm{~K}^{-1}$ and $\alpha_{c}=25.1 \times 10^{-6} \mathrm{~K}^{-1}$ are comparable to the experimental findings of $13.6 \times 10^{-6}$ and $29.8 \times 10^{-6} \mathrm{~K}^{-1}$, respectively. Our force field correctly predicts $\alpha_{c}$ to be larger than $\alpha_{a}$, which causes an elongation in the direction of the $c$-axis with increasing temperature. The anisotropy can be explained by considering that the sheets of mackinawite are held together by Van der Waals interactions. Their separation is energetically more favourable than stretching the crystal along the $a$-axis. The structural information and the thermal expansion coefficients of mackinawite are summarised in Table 2. For comparison, we have also listed the 
Table 2 Bulk properties of FeS

\begin{tabular}{lllllll}
\hline Method & $a(\AA)$ & $c(\AA)$ & $\mathrm{Fe}-\mathrm{Fe}(\AA)$ & $\mathrm{Fe}-\mathrm{S}(\AA)$ & $\alpha_{a}\left(\mathrm{~K}^{-1}\right)$ & $\alpha_{c}\left(\mathrm{~K}^{-1}\right)$ \\
\hline MM & 3.680 & 5.045 & 2.606 & 2.259 & $8.1 \times 10^{-6}$ & $25.1 \times 10^{-6}$ \\
DFT & 3.556 & 4.934 & 2.514 & 2.148 & - & - \\
Expt [41, 42] & 3.674 & 5.033 & 2.598 & 2.256 & $13.6 \times 10^{-6}$ & $29.8 \times 10^{-6}$ \\
\hline
\end{tabular}
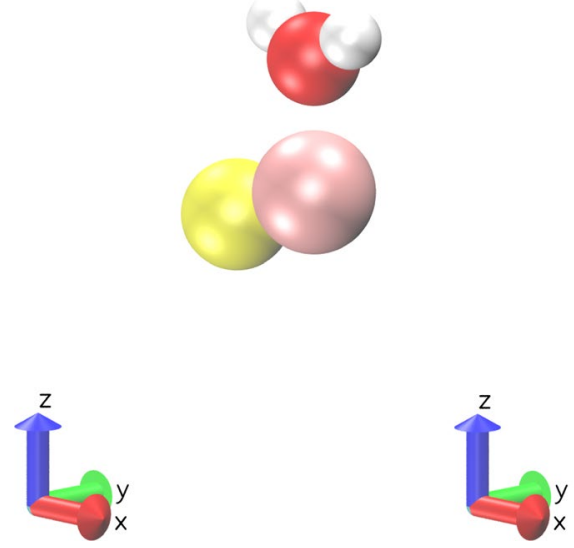

Fig. 2 Different relative orientations between $\mathrm{H}_{2} \mathrm{O}$ and $\mathrm{FeS}_{\text {mol }}$. The intermolecular interactions were scanned along the $z$-axis. Colour code: Fe pink, S yellow, $\mathrm{O}$ red, $\mathrm{H}$ white

experimental and DFT results, although the latter do not include temperature and are effectively at $0 \mathrm{~K}$.

\subsection{Derivation of the mineral-water parameters}

Next, we have derived the parameters describing the mineral/water interface. These were obtained by fitting interatomic potentials to ab initio interaction energies between $\mathrm{H}_{2} \mathrm{O}$ and $\mathrm{FeS}_{\mathrm{mol}}$, and the latter intended to be a minimal model of the atoms at the $\mathrm{FeS}$ surface. A similar approach has been adopted to develop $\mathrm{H}_{2} \mathrm{O}-\mathrm{CO}_{2}$ pairwise potentials to simulate the deposition of $\mathrm{CO}_{2}$ layers on water ice surfaces [43]. In this work, we have focused on two different $\mathrm{FeS}_{\mathrm{mol}}-\mathrm{H}_{2} \mathrm{O}$ orientations. In the first (Fig. 2, left), the water molecule is forced to keep a tetrahedral angle $\left(109.47^{\circ}\right)$ with $\mathrm{FeS}_{\mathrm{mol}}$, as we expect to happen for surface orientations exposing $\mathrm{Fe}$ atoms. In the second (Fig. 2, right), the water molecule is moved along an ideal $\mathrm{O}-\mathrm{H} \cdots \mathrm{S}$ hydrogen bond of $180^{\circ}$. As our goal was to design a force field for the $\mathrm{FeS} / \mathrm{H}_{2} \mathrm{O}$ interface which was compatible both with the existing FeS parameters described in Sect. 3.1, and the $\mathrm{SPC} / \mathrm{Fw}$ water model [24], during the fitting procedure, we have constrained all the original charges, together with the shell force constant. In addition, for consistency with the $\mathrm{FeS}$ force field, we have modelled the $\mathrm{Fe}-\mathrm{O}$ and $\mathrm{S}_{\text {shell }}-\mathrm{O}$ intermolecular interactions with Buckingham contributions.
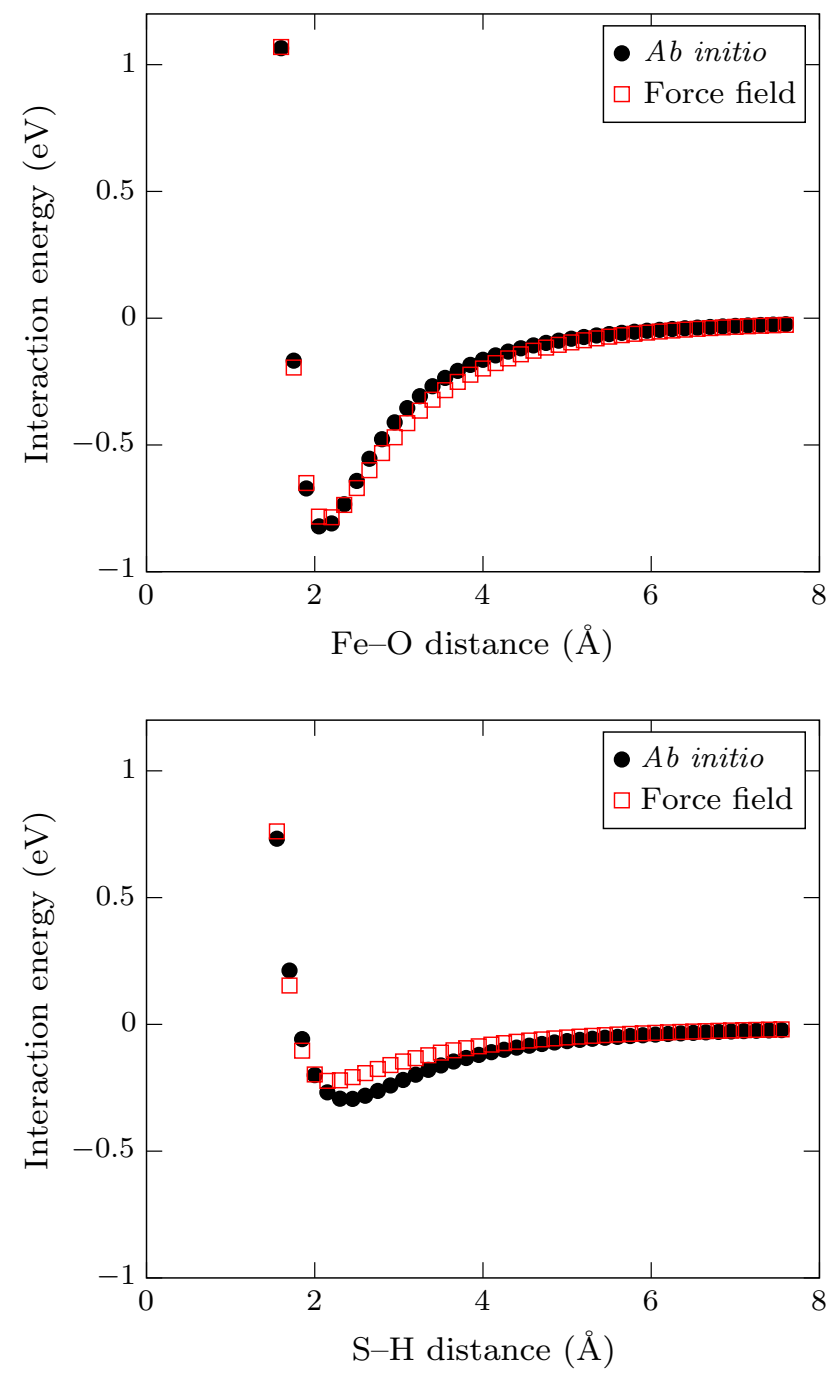

Fig. $3 \mathrm{Ab}$ initio and fitted interaction energies for the $\mathrm{FeS}_{\text {mol }}-\mathrm{H}_{2} \mathrm{O}$ orientations shown in Fig. 2

However, we have introduced a Lennard-Jones 12-10 term for the $\mathrm{S}_{\text {shell }}-\mathrm{H}$ pair, which reproduced the surface profiles better than a Buckingham potential. The pairwise terms of the $\mathrm{FeS}_{\mathrm{mol}}-\mathrm{H}_{2} \mathrm{O}$ energy are then given by:

$$
\begin{aligned}
U_{i j}= & A \exp \left(-\frac{r_{i j}}{\rho}\right)-\frac{C}{r_{i j}^{6}} \\
& +\varepsilon\left[5\left(\frac{\sigma}{r_{i j}}\right)^{12}-6\left(\frac{\sigma}{r_{i j}}\right)^{10}\right]+\frac{q_{i} q_{j}}{r_{i j}},
\end{aligned}
$$


Table 3 Force field parameters for the FeS-water interaction

\begin{tabular}{llll}
\hline Buckingham & $A(\mathrm{eV})$ & $\rho(\AA)$ & $C\left(\mathrm{eV} \AA^{6}\right)$ \\
\hline $\mathrm{Fe}-\mathrm{O}$ & 48294.40 & 0.160 & 0.00 \\
$\mathrm{~S}_{\text {shell-O }}$ & 5586.76 & 0.320 & 134.23 \\
Lennard-Jones 12-10 & $\varepsilon(\mathrm{eV})$ & $\sigma(\AA)$ & \\
$\mathrm{S}_{\text {shell }}-\mathrm{H}$ & 0.00927 & 2.82 & \\
\hline
\end{tabular}

Unless specified, a cut-off of $9.0 \AA$ was adopted

where the additional parameters with respect to Eq. 1, $\varepsilon$ and $\sigma$, are, respectively, the strength and the equilibrium distance of the Lennard-Jones 12-10 potential.

We present the ab initio interaction energies in Fig. 3, together with the respective fitted points. Both profiles are attractive, with the binding energy for the $\mathrm{Fe}-\mathrm{O}$ interaction stronger than the $\mathrm{S}-\mathrm{H}$. Despite the presence of the attracive Lennard-Jones 12-10 term, the strength of the S-H interaction energy around the minimum is underestimated by approximately $0.1 \mathrm{eV}$. One way to improve the agreement may be to release the constraint on the $\mathrm{FeS}_{\text {mol }}$ charges and/ or the shell force constant, a route which however we have not pursued here. The parameters which best reproduce the dissociation paths are listed in Table 3.

\subsection{Adsorption of water}

We have tested the interatomic potentials derived in Sect. 3.3 by investigating the adsorption energies and structures of undissociated water on three different orientations of FeS, namely the dominant (001), and the minor (100) and (011) surfaces [20]. Below, we show a comparison between the results obtained by our force field with those obtained ab initio by DFT.

We have evaluated the adsorption energy per water molecule, $E_{\mathrm{a}}$, according to

$$
E_{\mathrm{a}}=\frac{E_{\text {surf }+ \text { wat }}-E_{\text {surf }}-n E_{\text {wat }}}{n},
$$

where $E_{\text {surf+wat }}$ is the energy of the cell with adsorbed $n$ water molecules, while $E_{\text {surf }}$ and $E_{\text {wat }}$ are the energy of the cell with only the surface or an isolated water molecule, respectively.

\subsubsection{Mackinawite (001) surface}

Isolated molecule The (001) is the most stable mackinawite surface [20]. Here, according to DFT, a water molecule can only be physisorbed, forming two hydrogen bonds with two $\mathrm{S}$ atoms. These can belong to the same row along [100] (Fig. 4, top) or to two adjacent rows (Fig. 4, bottom). The two configurations are isoenergetic, with a binding energy of $-0.17 \mathrm{eV}$. This value less

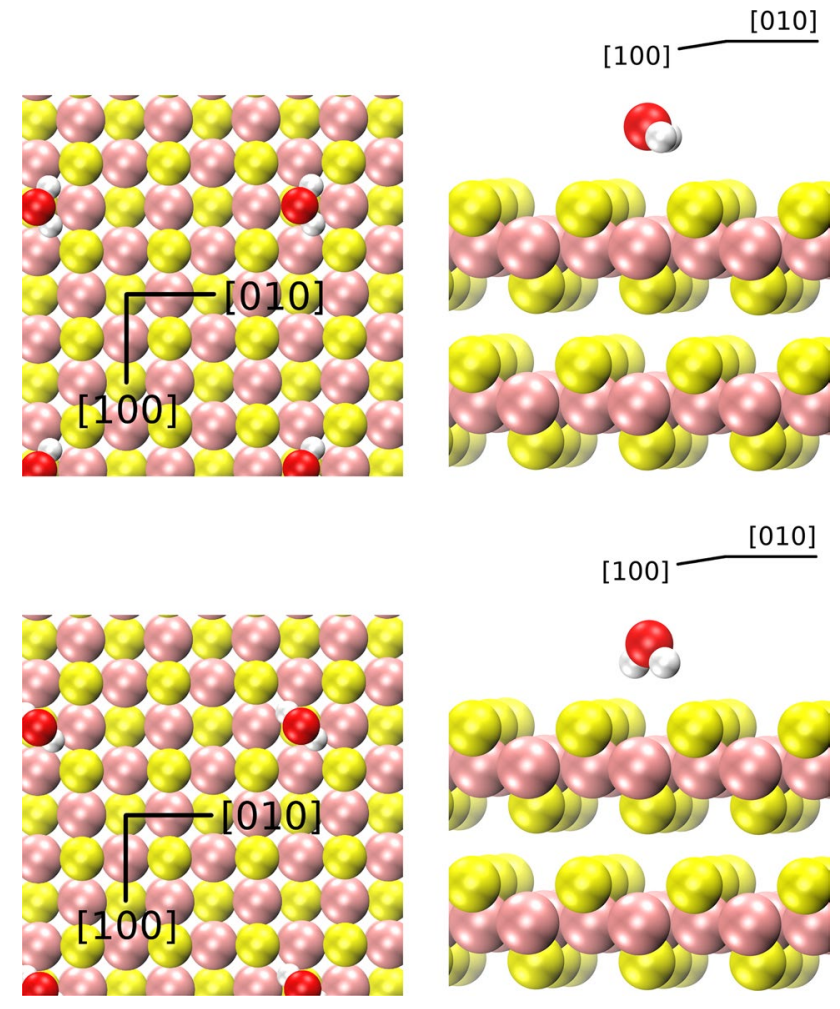

Fig. 4 Top and side view of the structures of isolated water on the mackinawite (001) surface forming two hydrogen bonds with two S atoms belonging to the same (top) or adjacent (bottom) rows along [100]. Colour code: Fe pink, $\mathrm{S}$ yellow, $\mathrm{O}$ red, $\mathrm{H}$ white

negative than the interaction energy of two water molecules $(-0.22 \mathrm{eV}[44])$ is typical of water physisorption on hydrophobic surfaces [10, 45, 46].

When optimised by MM, both the adsorption modes converge towards the first arrangement (Fig. 4, top), with a binding energy of $-0.15 \mathrm{eV}$. The key adsorption parameters of an isolated water molecule on the mackinawite (001) surface are summarised in Table 4.

Increased coverage Next, we have considered the adsorption of water at increased coverage. We are not concerned here with identifying the exact amount of molecules to model a monolayer nor with finding the global minimum. Instead, we would like to test the capability of the force field to reproduce a DFT local minimum at increased coverage. Accordingly, we have chosen to load the surface with $12 \mathrm{H}_{2} \mathrm{O}$ molecules (corresponding to a water coverage of $9.9 \mathrm{H}_{2} \mathrm{O} \mathrm{nm}{ }^{-2}$ ).

The structure optimised by DFT consists of a pattern of cyclic pentamers interacting weakly with the surface (Fig. 5, left). The stability of five-membered rings resembling those found in the gas phase [47] has also been reported by Zhang et al. for water physisorption on a different substrate [46]. When the DFT configuration is subsequently re-optimised by MM, the water-water and 

and main distances of an isolated $\mathrm{H}_{2} \mathrm{O}$ molecule on the mackinawite (001) surface
Table 4 Adsorption energies

\begin{tabular}{|c|c|c|c|c|c|c|}
\hline \multirow[t]{2}{*}{ Method } & \multicolumn{3}{|c|}{ Same row } & \multicolumn{3}{|c|}{ Adjacent rows } \\
\hline & $\overline{E_{\mathrm{a}}(\mathrm{eV})}$ & $\mathrm{S}-\mathrm{H}_{1}(\AA)$ & $\mathrm{S}-\mathrm{H}_{2}(\AA)$ & $\overline{E_{\mathrm{a}}(\mathrm{eV})}$ & $\mathrm{S}-\mathrm{H}_{1}(\AA)$ & $\mathrm{S}-\mathrm{H}_{2}(\AA)$ \\
\hline DFT & -0.17 & 2.83 & 2.81 & -0.17 & 2.73 & 2.72 \\
\hline MM & -0.15 & 2.59 & 2.59 & - & - & - \\
\hline
\end{tabular}
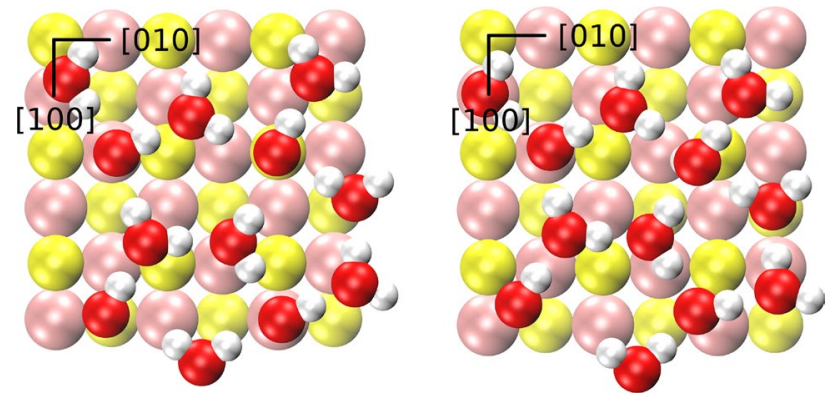

Fig. 5 Top view of the DFT (left) and MM (right) structures at increased water coverage on the mackinawite (001) surface. Colour code: Fe pink, S yellow, $\mathrm{O}$ red, $\mathrm{H}$ white

Table 5 Adsorption energies per molecule at increased water coverage on the mackinawite (001) surface

\begin{tabular}{lc}
\hline Method & $E_{\mathrm{a}}(\mathrm{eV})$ \\
\hline DFT & -0.57 \\
MM & -0.51 \\
\hline
\end{tabular}

water-surface interactions cooperate to preserve the hydrogen bond network (Fig. 5, right).

DFT and MM give adsorption energies per water molecule which are very close (Table 5) and more negative than the isolated molecule adsorption, reflecting the fact that water-water interactions are stronger than watersurface binding, and that the water layer is stabilised by intermolecular hydrogen bonds. This weak interaction with the surface can be appreciated especially from Fig. 6, which shows the local density of states (LDOS) of the $\mathrm{S}$ atoms in the topmost surface plane, with and without the adsorbed water layer. No important changes in the LDOS are observed, in line with a weak water-surface interaction.

\subsubsection{Mackinawite (100) and (011) surfaces}

Next, we have investigated the single molecule adsorption on the (100) and (011) faces of mackinawite. Our intent, here, is to show that the force field introduced is transferable among the low-index surfaces of mackinawite. For this reason, it is worth mentioning that on both

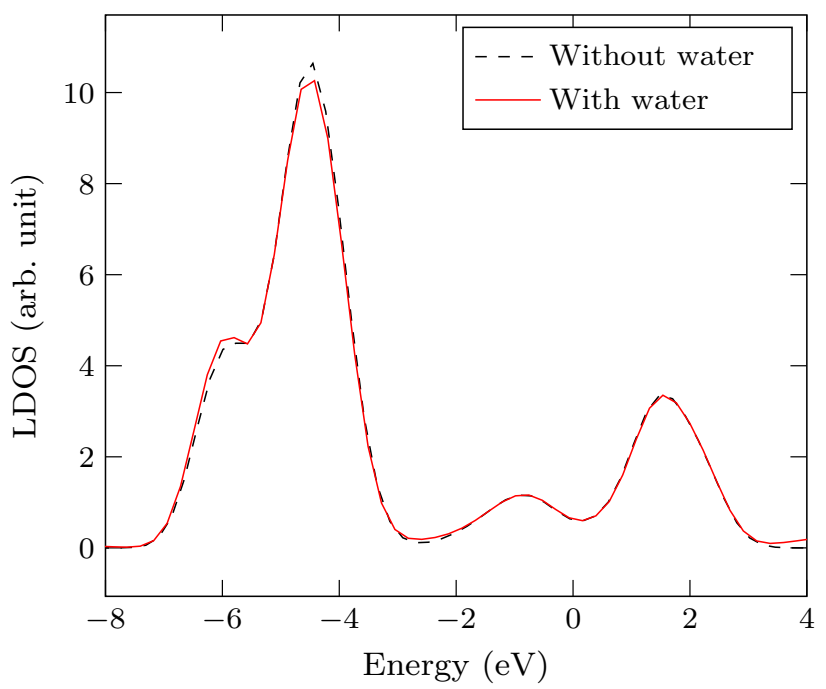

Fig. 6 Local density of states of the S atoms in the topmost plane of the (001) surface of mackinawite with and without the adsorbed water layer
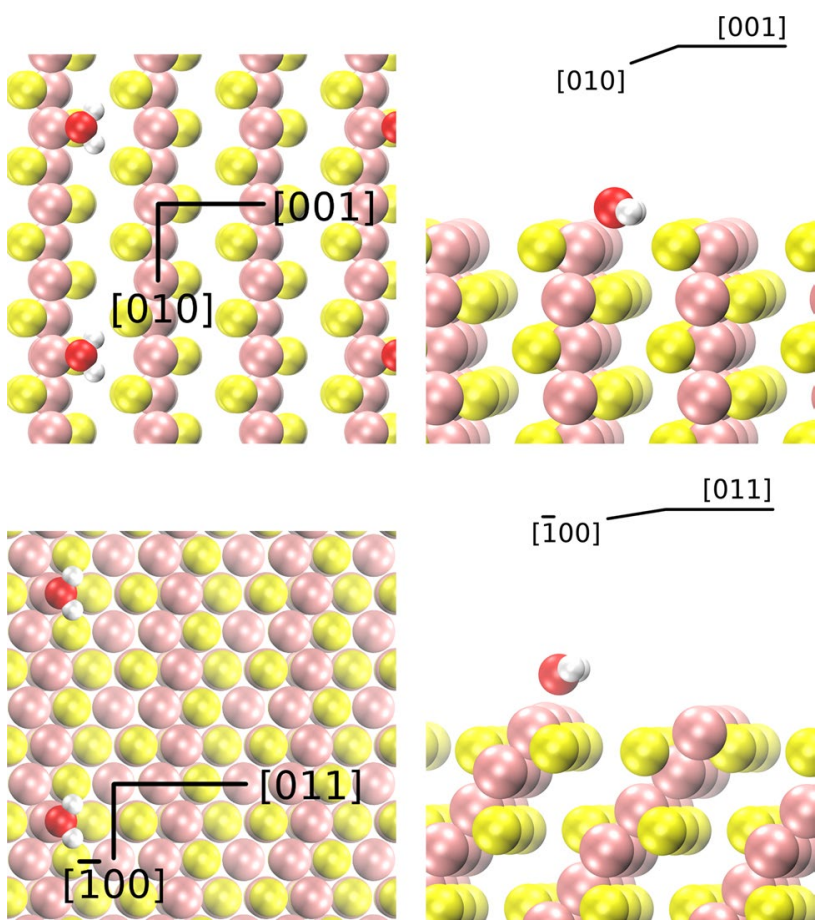

Fig. 7 Top and side view of the structures of isolated water on the mackinawite (100) (top) and (011) (bottom) surfaces. Colour code: Fe pink, $\mathrm{S}$ yellow, $\mathrm{O}$ red, $\mathrm{H}$ white 
Table 6 Adsorption energies and main distances of an isolated $\mathrm{H}_{2} \mathrm{O}$ molecule on the mackinawite (100) surface

\begin{tabular}{lllll}
\hline Method & $E_{\mathrm{a}}(\mathrm{eV})$ & $\mathrm{Fe}-\mathrm{O}(\AA)$ & $\mathrm{S}-\mathrm{H}_{1}(\AA)$ & $\mathrm{S}-\mathrm{H}_{2}(\AA)$ \\
\hline DFT & -1.02 & 2.03 & 2.45 & 2.42 \\
MM & -0.90 & 1.99 & 2.53 & 2.51 \\
\hline
\end{tabular}

Table 7 Adsorption energies and main distances of an isolated $\mathrm{H}_{2} \mathrm{O}$ molecule on the mackinawite (011) surface

\begin{tabular}{lll}
\hline Method & $E_{\mathrm{a}}(\mathrm{eV})$ & $\mathrm{Fe}-\mathrm{O}(\AA)$ \\
\hline DFT & -0.81 & 2.06 \\
MM & -0.69 & 2.01 \\
\hline
\end{tabular}

the mackinawite (100) and (011) surfaces, the most stable structures obtained by DFT and MM describe the same minimum.

The (100) surface is the most reactive towards water, providing the most negative adsorption energy among the three surfaces studied here $(-1.02 \mathrm{eV})$. On this face, the water oxygen binds to a topmost $\mathrm{Fe}$, while two hydrogen bonds with two $\mathrm{S}$ atoms of the adjacent sheet are formed (Fig. 7, top). The strength of the adsorption and the geometric parameters is reproduced very accurately by our force field (Table 6).

Similarly, on the (011) termination, the water molecule is adsorbed on top of a Fe atom (Fig. 7, bottom). However, here, the interaction is less strong $(-0.81 \mathrm{eV})$, due to the absence of additional hydrogen bonds. The predicted binding energy is within the typical force field expectations, while the agreement with the $\mathrm{Fe}-\mathrm{O}$ distance calculated by DFT remains quantitative (Table 7).

\subsection{Water intercalated between FeS sheets}

Finally, we have tested the transferability of the force field to the aqueous phase, under typical hydrothermal vent conditions. In particular, we have investigated the properties of thin films of water inside FeS sheets and validated our force field against the ab initio MD results, based on DFT, by Wittekindt and Marx [18]. In their "system A", one of the two FeS interlayer distances of a $4 \times 4 \times 2$ bulk unit cell was expanded to $11.70 \AA$. In order to reproduce a pressure of $20 \mathrm{MPa}$, at a temperature of $500 \mathrm{~K}$, the resulting cavity between the $64 \mathrm{FeS}$ units was filled with 49 water molecules. In our classical approach, however, we have used a larger unit cell, consisting of $256 \mathrm{FeS}$ units and 196 water molecules (Fig. 8). Both Fe planes were kept fixed during the dynamics.

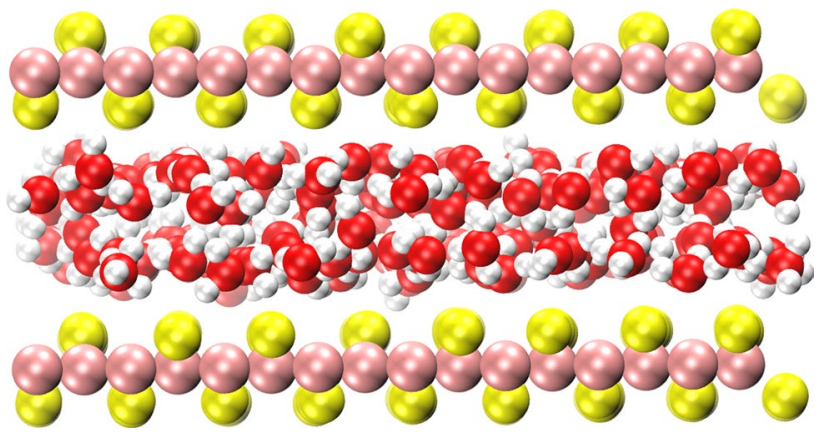

Fig. 8 The unit cell of system A employed in our MD simulations

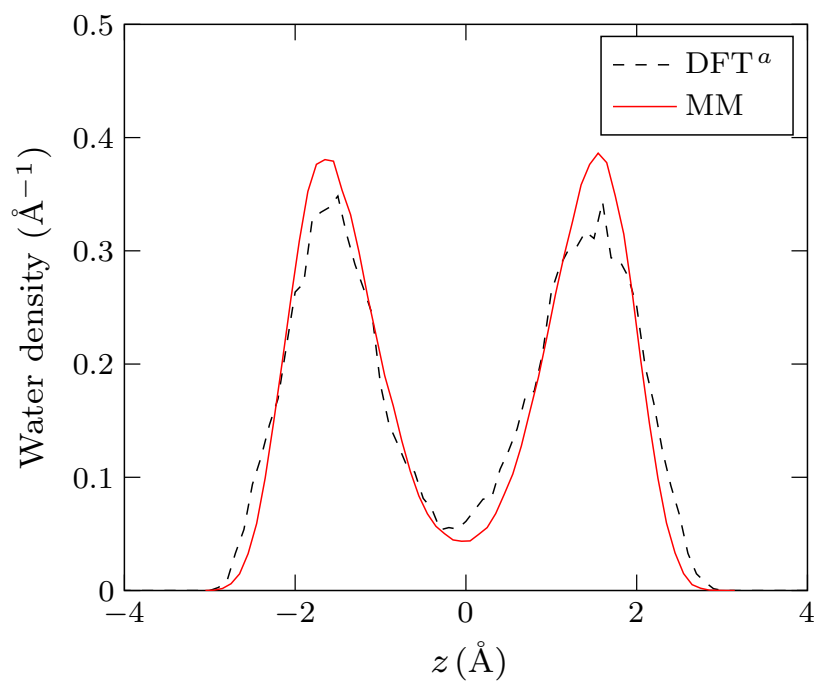

Fig. 9 Density profiles of water (normalised to 1) along the direction normal to the surface. The origin of the $z$ coordinate corresponds to the central plane of system A. ${ }^{a}$ From reference [18]

Figure 9 compares the MM and DFT density profiles of water. In our MM simulation, two layers of water are formed, clearly distinguishable by the maxima at positions $\pm 1.6 \AA$. In between them, the density is very low, shown by a minimum in correspondence with the central plane of the cell. This structural behaviour of water reproduces that found by ab initio MD [18], both qualitatively and quantitatively.

The distribution of the number of hydrogen bonds formed per water molecule is reported in Fig. 10. As a criterion for hydrogen bonding, we have adopted a $\mathrm{O}-\mathrm{O}$ distance smaller than $3.5 \AA$ and a $\mathrm{O}-\mathrm{H}-\mathrm{O}$ angle larger than $150^{\circ}$ [48]. The average of the distribution is 1.98 hydrogen bonds per water molecule, very close to the ab initio value of 1.96. The maximum is at two hydrogen bonds, but with a significant fraction of water molecules having one or three. The fraction of molecules with zero or four hydrogen 


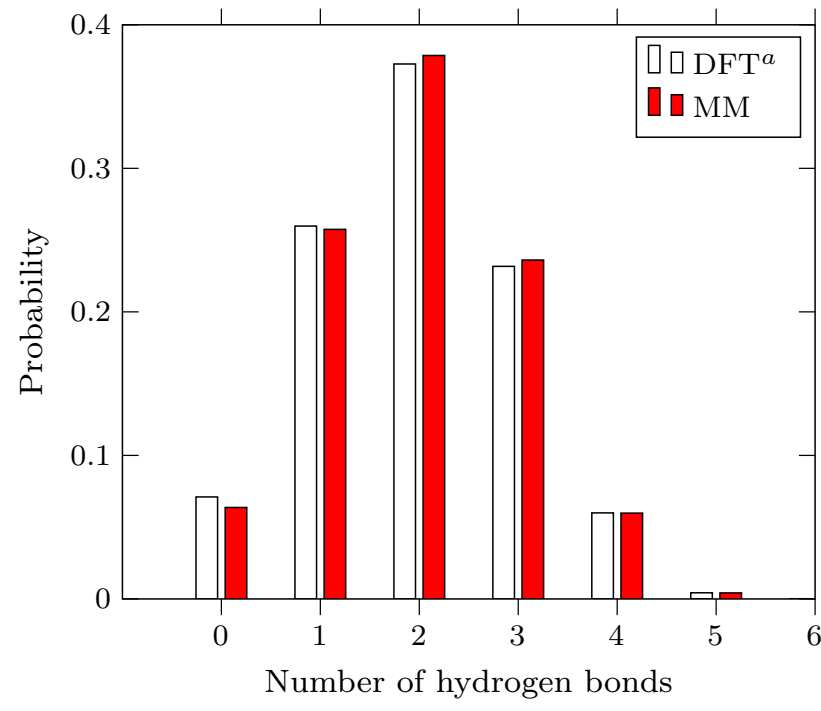

Fig. 10 Distribution of the number of hydrogen bonds formed per water molecule. ${ }^{a}$ From reference [18]

bonds is less than 0.1 . These features are all present in the ab initio distribution [18], as shown in Fig. 10.

\section{Conclusions}

We have introduced a force field for the description of the mackinawite/water interface, which can be reliably used in MD simulations involving aqueous mackinawite.

The addition of a simple three-body term to the existing interatomic potential model for mackinawite was sufficient to avoid the emergence of trigonal-planar coordinated irons during $\mathrm{MD}$, while reproducing well the structural properties and thermal behaviour of mackinawite. In order to derive the missing interaction parameters between the mineral and water, we have fitted two ab initio interaction energy curves between a single $\mathrm{H}_{2} \mathrm{O}$ molecule and $\mathrm{FeS}_{\text {mol }}$ by a sum of pairwise potentials. As shown by the parallel DFT investigation of water adsorption on the low-index mackinawite faces, the resulting force field reliably predicts the energetics and the geometries of the most stable configurations on defect-free mineral surfaces, which lends support to our procedure. Further validation is provided by the description of thin films of water within $\mathrm{FeS}$ sheets, where the structural properties at extreme thermodynamic conditions agree quantitatively with the $a b$ initio data in the literature.

One limitation of our approach is the lack of parameters for dissociated water, which is consistent with the $\mathrm{SPC} / \mathrm{Fw}$ model. While on the dominant (001) surface this is justified by the finding that DFT predicts water to be only physisorbed, dissociative adsorption may play a role on the minority faces, although spontaneous dissociation was not observed by DFT. We intend to include an investigation on water dissociation in a future work.

Acknowledgments We are very grateful to Prof. Marx for providing us with the ab initio data of Figs. 9 and 10. This work was supported by the Natural Environment Research Council (Grant NE/ J010626/1). This work used the ARCHER UK National Supercomputing Service (http://www.archer.ac.uk). The authors acknowledge the use of the UCL Legion High Performance Computing Facility (Legion@UCL), and associated support services, in the completion of this work. NHdL thanks the Royal Society for an Industry Fellowship.

Open Access This article is distributed under the terms of the Creative Commons Attribution 4.0 International License (http://creativecommons.org/licenses/by/4.0/), which permits unrestricted use, distribution, and reproduction in any medium, provided you give appropriate credit to the original author(s) and the source, provide a link to the Creative Commons license, and indicate if changes were made.

\section{References}

1. Guevremont JM, Bebie J, Elsetinow AR, Strongin DR, Schoonen MA (1998) Environ Sci Technol 32(23):3743

2. Descostes M, Vitorge P, Beaucaire C (2004) Geochim Cosmochim Acta 68(22):4559

3. Wächtershäuser G (1988) Syst Appl Microbiol 10(3):207

4. Knipe S, Mycroft J, Pratt A, Nesbitt H, Bancroff G (1995) Geochim Cosmochim Acta 59(6):1079

5. Nesbitt H, Muir I (1994) Geochim Cosmochim Acta 58(21):4667

6. De Leeuw NH, Parker SC, Sithole HM, Ngoepe PE (2000) J Phys Chem B 104(33):7969

7. Stirling A, Bernasconi M, Parrinello M (2003) J Chem Phys 118(19):8917

8. Philpott MR, Goliney IY, Lin TT (2004) J Chem Phys 120(4): 1943

9. Sit PHL, Cohen MH, Selloni A (2012) J Phys Chem Lett 3(17):2409

10. Chen J, Long X, Chen Y (2014) J Phys Chem C 118(22):11657

11. Vorlicek TP, Kahn MD, Kasuya Y, Helz GR (2004) Geochim Cosmochim Acta 68(3):547

12. Bone SE, Bargar JR, Sposito G (2014) Environ Sci Technol 48(18): 10681

13. Hyun SP, Davis JA, Sun K, Hayes KF (2012) Environ Sci Technol 46(6):3369

14. Terranova U, de Leeuw NH (2014) Phys Chem Chem Phys 16(26): 13426

15. Beinert H, Holm RH, Münck E (1997) Science 277(5326):653

16. Martin W, Russell MJ (2003) Philos Trans R Soc B 358(1429):59

17. Mielke RE, Robinson KJ, White LM, McGlynn SE, McEachern K, Bhartia R, Kanik I, Russell MJ (2011) Astrobiology 11(10):933

18. Wittekindt C, Marx D (2012) J Chem Phys 137(5):054710

19. Muñoz-Santiburcio D, Wittekindt C, Marx D (2013) Nat Commun 4:2349

20. Devey AJ, Grau-Crespo R, De Leeuw NH (2008) J Phys Chem C 112(29): 10960

21. Dick B Jr, Overhauser A (1958) Phys Rev 112(1):90

22. Dzade NY, Roldan A, de Leeuw NH (2013) J Chem Phys 139(12): 124708

23. Ohfuji H, Rickard D (2006) Earth Planet Sci Lett 241(1):227

24. Wu Y, Tepper HL, Voth GA (2006) J Chem Phys 124(2):024503 
25. Todorov IT, Smith W, Trachenko K, Dove MT (2006) J Mater Chem 16(20):1911

26. Hoover WG (1985) Phys Rev A 31(3):1695

27. Essmann U, Perera L, Berkowitz ML, Darden T, Lee H, Pedersen LG (1995) J Chem Phys 103(19):8577

28. Mitchell P, Fincham D (1993) J Phys Condens Matter 5(8):1031

29. Frisch M, Trucks G, Schlegel HB, Scuseria G, Robb M, Cheeseman J, Scalmani G, Barone V, Mennucci B, Petersson G (2009) Gaussian 09 (Revision C.01), Gaussian, Inc., Wallingford

30. Dunning TH Jr (1989) J Chem Phys 90:1007

31. Boys S, Bernardi Fd (1970) Mol Phys 19(4):553

32. Gale JD (1997) J Chem Soc Faraday Trans 93(4):629

33. Gale JD, Rohl AL (2003) Mol Simul 29(5):291

34. Kresse G, Hafner J (1993) Phys Rev B 47(1):558

35. Kresse G, Furthmuller J (1996) Comput Mater Sci 6(1):15

36. Grimme S (2006) J Comput Chem 27(15):1787

37. Dzade NY, Roldan A, de Leeuw NH (2014) Phys Chem Chem Phys 16(29): 15444

38. Perdew JP, Burke K, Ernzerhof M (1996) Phys Rev Lett 77(18):3865
39. Blöchl PE (1994) Phys Rev B 50(24):17953

40. Monkhorst HJ, Pack JD (1976) Phys Rev B 13(12):5188

41. Lennie AR, Redfern S, Schofield P, Vaughan D (1995) Miner Mag 59(397):677

42. Lennie AR, Redfern SA, Champness PE, Stoddart CP, Schofield PF, Vaughan DJ (1997) Am Miner 82(3):302

43. Karssemeijer L, de Wijs G, Cuppen H (2014) Phys Chem Chem Phys 16(29): 15630

44. Klopper W, van Duijneveldt-van De Rijdt JGCM, van Duijneveldt FB (2000) Phys Chem Chem Phys 2(10):2227

45. Jenness GR, Karalti O, Jordan KD (2010) Phys Chem Chem Phys 12(24):6375

46. Zhang G, Al-Saidi W, Myshakin EM, Jordan KD (2012) J Phys Chem C 116(32):17134

47. Ramírez F, Hadad C, Guerra D, David J, Restrepo A (2011) Chem Phys Lett 507(4):229

48. Luzar A, Chandler D (1996) Phys Rev Lett 76(6):928 